\title{
Discovery of genetic difference between asthmatic children with high IgE level and normal IgE level by whole genome linkage disequilibrium mapping using 763 autosomal STR markers
}

Received: 11 January 2005/ Accepted: 22 March 2005/Published online: 21 May 2005

(C) The Japan Society of Human Genetics and Springer-Verlag 2005

\begin{abstract}
The genome-wide linkage disequilibrium screen for loci associated with genetic difference between allergic and nonallergic asthma was conducted with 763 autosomal STR markers and included 190 asthmatic children. Evidence for association with differences between the two forms of asthma was observed for 36 STR markers. Marker-to-marker synergetic effect and by simulation resampling tests revealed D5S2011, D6S305, and D9S286 were important loci in allergic asthma while D6S1574, D8S1769, and D19S226 were important in nonallergic asthma. Our results show strong genetic evidence that these markers play an important role in defining allergic and nonallergic asthma and provides important candidates of susceptible genes in these two categories of asthma. This study further shows that asthma is, indeed, a heterogeneous group of underlying diseases and, although with similar clinical phenotypes, may have different clinical severities, outcomes, and need more tailor-made management.
\end{abstract}

Keywords Allergic asthma - Nonallergic asthma · STR markers · Linkage disequilibrium mapping · Synergetic effect

\section{J.-Y. Wang}

Department of Pediatrics, Institute of Molecular Medicine, College of Medicine, National Cheng-Kung University, Tainan, Taiwan

C. G.-J. Lin · M. S.-J. Bey · L. Wang · F. Y.-F. Lin L. Huang · L. S.-H. Wu ( $\)$

Research Development Division, Vita Genomics Inc., 7Fl., No. 6, Sec. 1, Jungshing Rd., Taipei County, Wugu Shiang, 248, Taiwan

E-mail: lawrence.wu@vitagenomics.com

Tel.: + 886-2-89769123

Fax: + 886-2-89769523

L. Wang

Division of Molecular and Genomic Medicine,

National Health Research Institutes, Taipei, Taiwan

\section{Introduction}

Asthma is a chronic airway inflammatory disease, affects nearly 155 million individuals worldwide, and is a multifactorial complex disease and phenotypically heterogeneous (Cookson 1999). Children who suffered from asthmatic diseases are more prone to have sensitized allergens detected by skin prick tests and/or by total and allergen-specific IgE antibodies in the serum, hence the extrinsic or allergic asthma. The timing and degree of allergen sensitization and total serum IgE levels are also the major determinants for the clinical severity of allergic asthma. Nonallergic asthma, or intrinsic asthma, another group of asthmatic patients, is not demonstrably allergic to common allergens by skin prick test. Serum total $\operatorname{IgE}$ concentrations are usually within normal ranges. These patients are usually older than their allergic counterparts and have onset of symptoms in later life, often with a more severe clinical course. There is a predominance in the female gender, and association of nasal polyps and aspirin sensitivity occurs more frequently in the nonallergic asthmatic (Rackeman 1947; Bentley et al. 1992; Humbert et al. 1996a, 1999). From these distinctive clinical manifestations, although the pathological findings are similar, nonallergic asthma is viewed as a different entity to allergic asthma.

In contrast, some authors have argued that intrinsic asthmatics are allergic to an as yet undetected allergen and suggest a role for IgE and atopy in nonallergic asthma and they could, therefore, benefit from allergen avoidance, as previously demonstrated in atopic asthmatics (Dorward et al. 1988; Burrows et al. 1989). Analysis of bronchial mucosal expression of "proeosinophilic" and "pro-atopic" markers, i.e., IL-3, IL-4, IL-5, IL-13, GM-CSF, RANTES, MCP-3, IgE, and Fc $\epsilon$ RI, demonstrates that there are more similarities than differences in immunopathology between allergic 
Fig. 1 Result of entire autosomal region screened for loci associated with the differences between asthmatics with high IgE and normal IgE. Tested loci (STR markers) are arranged by number from $\mathrm{p}$ terminus to q-terminus in each chromosome. The graphic representation shows the allelic association on 22 autosomal chromosomes. $X$-axis is STR marker's genetic location on chromosome 5 from p-terminus to q-terminus. $Y$-axis is natural logarithm of Monte-Carlo simulation $p$ value. $Y=3$ is almost equal to $p=0.05$. The numbers in the $X$-axis indicate the genetic location of significant loci
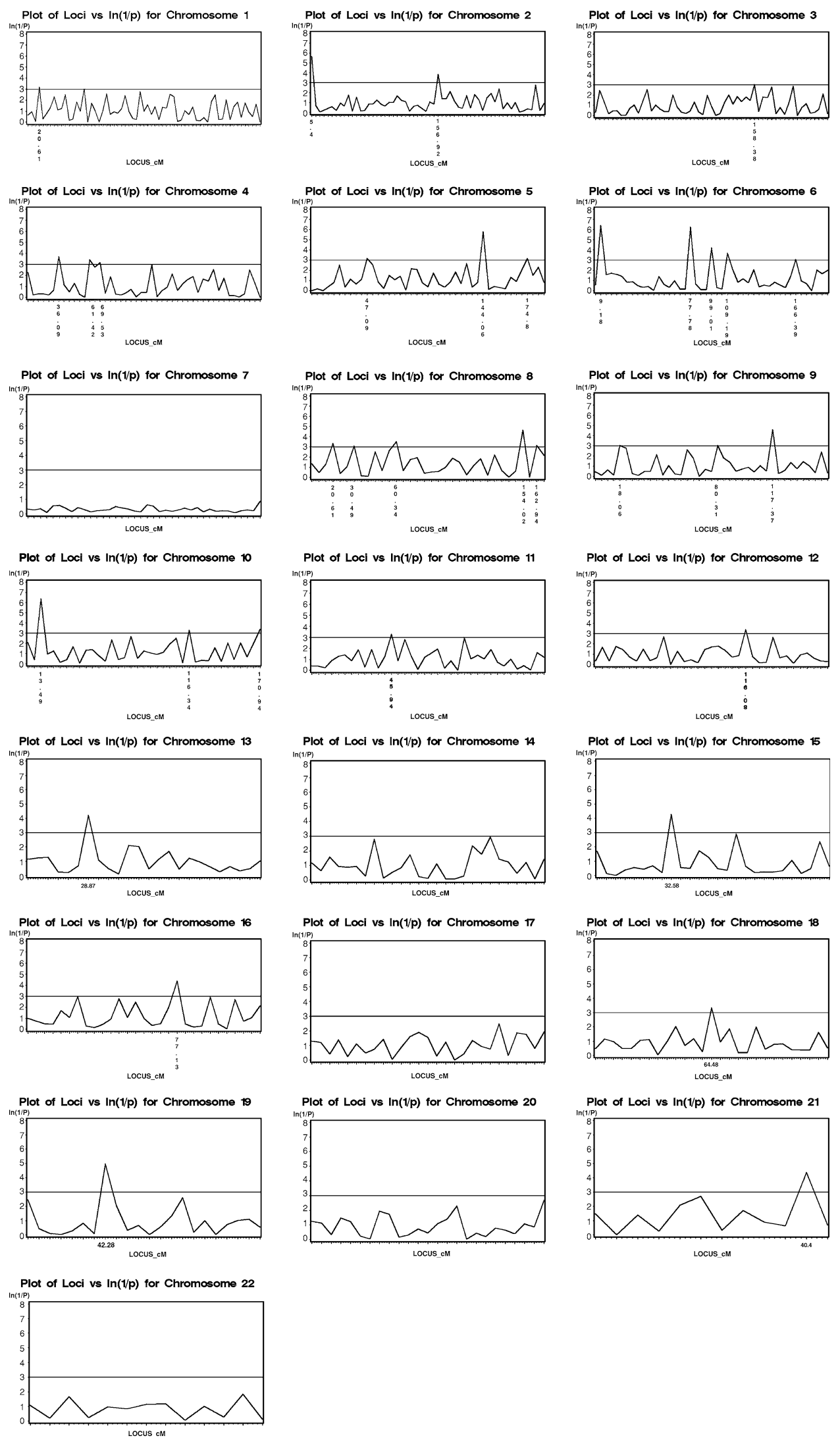

and nonallergic asthma (Humbert et al. 1996a, 1996b, 1997a, 1997b, 1999; Ying et al. 1997, 1999). The only difference seems to be a strong macrophage signal in biopsies from nonallergic asthma patients compared with those from allergic asthmatics. This could represent macrophage dysfunction or simply be a reflection of age 
Table 1 Summary and test results of the allele and/or genotype frequency of 35 STR markers, which were significantly different between $\operatorname{IgE}$ high $(\mathrm{H})$ and $\operatorname{IgE}$ normal $(\mathrm{N})$ asthmatics

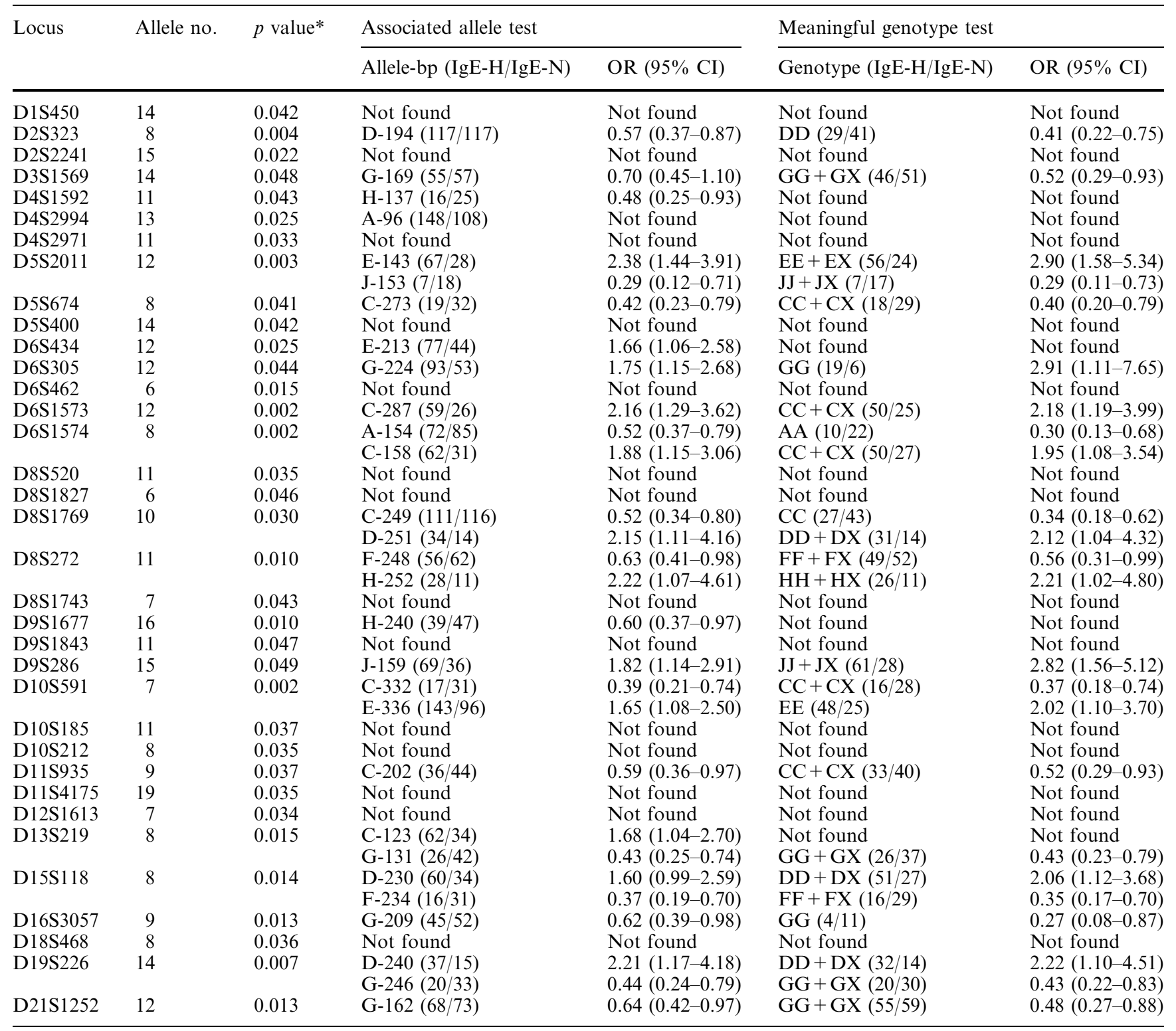

* Monte-Carlo estimates of exact $p$ values

and length of disease rather than a basic difference in the pathological mechanism between these two forms of asthma (Humbert et al. 1999). But still, these findings cannot fully explain why nonallergic asthma, without elevation of total serum IgE, has a similar pattern of allergen-induced bronchial inflammation, either in the underlined etiology or in the disease development of this form of asthma.

Recently, Holgate and Davies (2001) postulated that epithelial damage and allergy-prone $\mathrm{T}_{\mathrm{H}} 2$ cytokines can act in concert to cause a functional disturbance of the epithelial-mesenchymal trophic unit (EMTU), which leads to myofibroblast activation and induction of inflammatory and remodeling responses characteristic of chronic asthma (Holgate and Davies 2001). This model differs from the traditional sequential view of asthma pathogenesis by setting the structural abnormalities in parallel with $\mathrm{T}_{\mathrm{H}} 2$ cytokine-induced inflammation. Because allergic diseases, including asthma, rhinitis, and eczema, are caused by both environmental and genetic factors, the expression of allergic asthma is dependent on inheritance of local susceptibility genes, which have the potential to interact with the atopy predisposition, whereas nonallergic asthma may have a different set of responsible genes to the environmental stimuli that lead to EMTU damage and chronic airway inflammation in the absence of IgE elevation (Davies et al. 2003).

Based on this hypothesis, the aim of the present study was to investigate whether there is a different set(s) of susceptible genes between allergic and nonallergic 
Table 2 Result of logistic regression (data adapted from SAS output) and discrimination equation ${ }^{\text {a }}$

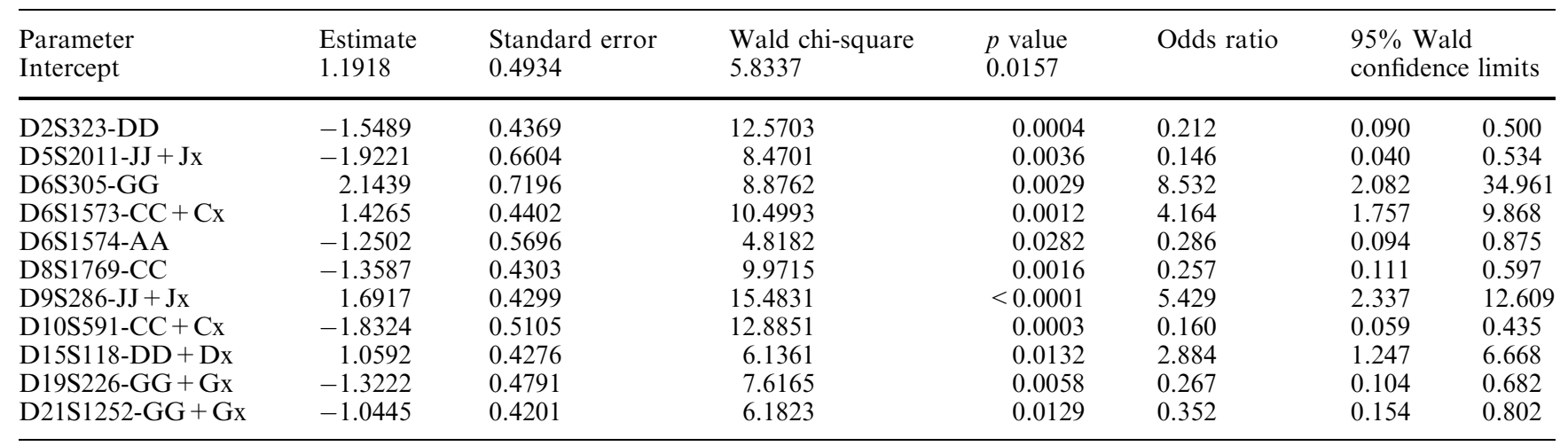

${ }^{a}$ Discrimination equation: logit $p=1.1918$ (intercept estimate) $+\Sigma$ estimate $\times[1$ (meaningful genotype existed) or 0 (meaningful genotype did not exist $)] \cdot p=\mathrm{e}^{\log i t} p /\left(\mathrm{e}^{\operatorname{logit} p}+1\right)$

asthma in children based on total serum IgE levels and responsiveness to common aeroallergen. We conducted a genome scan using 763 autosomal STR markers to search the loci associated with these two types of asthma in Taiwanese, non-obviously related, children selected by narrow phenotype definitions. Our data revealed evidence of genetic differences between allergic and nonallergic asthma. The results implied chronic asthma initiated from allergy and/or nonallergy factors was determined by different susceptibility genes.

\section{Materials and methods}

\section{Clinical sample collection}

Our study population consisted of asthmatic children aged between 1 and 12 years old, and the Ethical and Clinical Trial Committee of the National Cheng-Kung University Hospital approved this study protocol. All participants or their guardian, after being well informed of the study protocol and signing the consent forms, answered a modified British Medical Society respiratory questionnaire, which is exactly the same as the European Community Respiratory Health Survey (ECHRS), which has similar validity as the ISAAC (Burney et al.1994; Pearce et al. 2000), as well as additional questions pertinent to the diagnosis and assessment of asthma. Pulmonary function was tested using standard methods, which included spirometry before and after the administration of two puffs of inhaled salbutamol $(200 \mu \mathrm{g} / \mathrm{puff})$. The definition of asthma included: (1) History of wheezing and shortness of breath during or without concurrent respiratory infections, (2) chronic cough for more than 1 month and being diagnosed by a physician of the presence of wheezing episode(s), (3) bronchodilator test that confirmed the positive response of an increase of $15 \%$ in forced expiratory volume in $1 \mathrm{~s}$ (FEV1). Other evaluations included skin prick tests for responsiveness to six common aeroallergens, a differential blood count (including total eosinophil count), and measures of total serum $\operatorname{IgE}$, as well as IgE specific to house dust and mixed pollens using the Unicap system (Pharmacia Diagnostic, Sweden). A positive skin test was defined as the presence of $\geq 1$ reaction with a wheal diameter $\geq 5 \mathrm{~mm}$. Total serum $\mathrm{IgE}$ was measured by solid-phase immunoassay (Pharmacia IgE EIA; Pharmacia Diagnostics). The confirmed asthmatic children were further divided by their serum IgE levels: the allergic group (105 subjects) had high IgE serum concentrations $(\geq 1,000 \mathrm{IU} / \mathrm{ml})$ and sensitized to at lease one aeroallergen; in the nonallergic group ( 85 subjects), $\operatorname{IgE}$ serum levels were within normal range $(\leq 200 \mathrm{IU} / \mathrm{ml})$, and there was no detectable allergen sensitization.

\section{DNA preparation}

Genomic DNAs were extracted from 190 unrelated Taiwanese children. DNA was isolated from blood sample using QIAamp DNA blood kit according to the manufacture's instructions. The isolated genomic DNA was quality-checked by agarose gel electrophoresis analysis, the quantity was determined spectrophotometrically, and it was stored at $-80^{\circ} \mathrm{C}$.

\section{Microsatellite genotyping}

Genotyping was performed using the ABI PRISM Linkage Mapping Sets HD-5 (811 markers) to provide coverage of human genome at $5 \mathrm{cM}$ average resolution. Each marker set included a fluorescence-labeled forward primer and a tailing reverse primer. The PCR amplifications were carried out according to the manufacturer's instructions. The PCR products were separated on ABI 3700 DNA analyzers. The use of GeneScan 500 LIZ as the internal size standard assisted polymorphic fragment-length calling and allowed more accurate allele calling and unambiguous comparison of data across experimental conditions. 

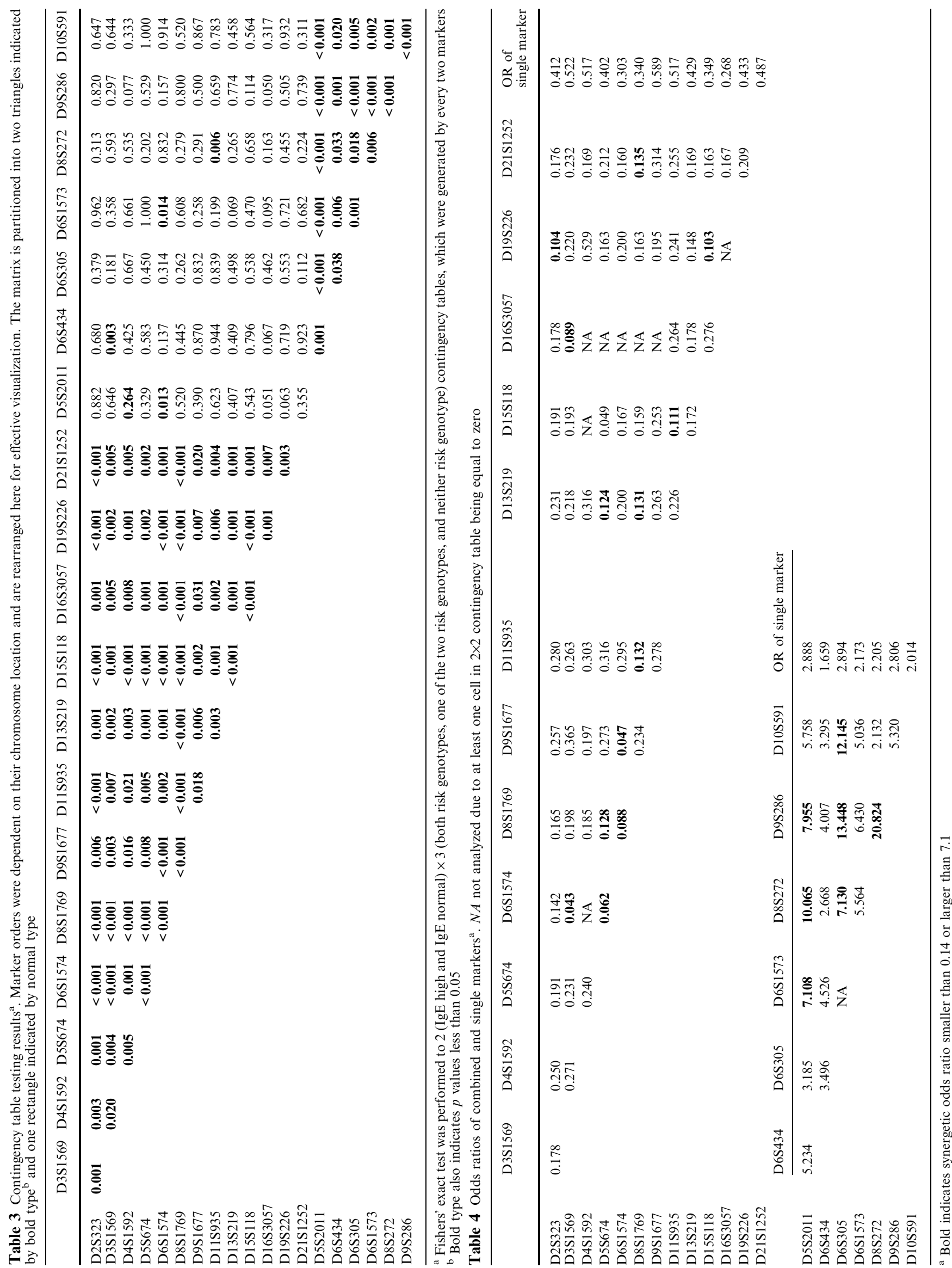
Table 5 The results of odds ratio after being simulated 10,000 times $^{\mathrm{a}}$. $N A$ not analyzed due to at least one cell in $2 \times 2$ contingency table being equal to zero

\begin{tabular}{|c|c|c|c|c|c|c|c|c|c|c|c|c|}
\hline & D3S1569 & D4S1592 & D5S674 & D6S1574 & D8S1769 & D9S1677 & D11S935 & D13S219 & D15S118 & D16S3057 & D19S226 & $\mathrm{D} 21 \mathrm{~S} 1252$ \\
\hline D2S323 & 0.171 & 0.233 & 0.180 & 0.128 & 0.159 & 0.248 & 0.273 & 0.224 & 0.180 & 0.166 & 0.094 & 0.170 \\
\hline D3S1569 & & 0.261 & 0.223 & 0.054 & 0.192 & 0.356 & 0.255 & 0.211 & 0.185 & 0.110 & 0.211 & 0.223 \\
\hline D4S1592 & & & 0.217 & NA & 0.169 & 0.179 & 0.287 & 0.295 & NA & NA & 0.507 & 0.157 \\
\hline D5S674 & & & & 0.078 & 0.117 & 0.260 & 0.307 & 0.112 & 0.061 & NA & 0.150 & 0.205 \\
\hline D6S1574 & & & & & 0.083 & 0.059 & 0.278 & 0.183 & 0.158 & NA & 0.187 & 0.151 \\
\hline D8S1769 & & & & & & 0.226 & 0.125 & 0.124 & 0.147 & NA & 0.154 & 0.130 \\
\hline D9S1677 & & & & & & & 0.269 & 0.254 & 0.238 & 0.166 & 0.181 & 0.306 \\
\hline D11S935 & & & & & & & & 0.219 & 0.101 & 0.333 & 0.231 & 0.249 \\
\hline D13S219 & & & & & & & & & 0.157 & 0.222 & 0.136 & 0.162 \\
\hline D15S118 & & & & & & & & & & 0.345 & 0.097 & 0.156 \\
\hline D16S3057 & & & & & & & & & & & NA & 0.150 \\
\hline D19S226 & & & & & & & & & & & & 0.202 \\
\hline & D6S434 & D6S305 & D6S1573 & D8S272 & D9S286 & D10S591 & & & & & & \\
\hline D5S2011 & 5.127 & 2.998 & 6.957 & 9.774 & 7.772 & 5.624 & & & & & & \\
\hline D6S434 & & 3.401 & 4.435 & 2.606 & 3.939 & 3.235 & & & & & & \\
\hline D6S305 & & & NA & 6.803 & 12.850 & 11.733 & & & & & & \\
\hline D6S1573 & & & & 5.423 & 6.270 & 4.912 & & & & & & \\
\hline D8S272 & & & & & 20.368 & 2.008 & & & & & & \\
\hline D9S286 & & & & & & 5.197 & & & & & & \\
\hline
\end{tabular}

${ }^{a}$ Bold indicates synergetic odds ratio smaller than 0.14 or larger than 7.1

Genotypes were initially scored using Genescan and Genotyper (ABI) software and were then verified independently by three individuals without prior knowledge of phenotype.

\section{Statistical analysis}

To evaluate STR markers associated with the difference between IgE-high and IgE-normal asthmatics, the STR markers with significantly different allele frequencies in two asthma subtypes were sought by $\chi^{2}$ test, in which the significant level was estimated by Monte-Carlo simulation (Sham and Curtis 1995). Alleles in significant marker loci were tested for linkage disequilibrium with null causative or signature polymorphism by analysis with the contingency table. The significant alleles were tested by odds ratio as risk factors. Genotype contingency tables were constructed according to specific alleles with significant $p$ values and odds ratio. The meaningful genotypes were defined by significant $\chi^{2}$ and odds ratio. Information on the genotype of all significant markers was collected, and the data set was transformed into a binary category, with the meaningful genotype and the others represented by " 1 " and " 0 ," respectively. In other words, a genotype showing association (meaningful genotype) was coded 1, and a genotypes showing no association was coded 0 in the binary data set. Discrimination equation was performed by logistic regression using the transformed binary data set.

For elucidating marker-marker synergetic effect to asthma subtype, the binary information of each of the two markers was combined as a single factor. Three categories were generated by combining two markers: both were risk genotypes, one of the two was a risk genotype, and neither was a risk genotype. The associ- ation between marker-to-marker synergetic effect and IgE status was tested by $2 \times 3$ contingency table using Fisher's exact test. Odds ratios of two-marker synergetic effect were generated using both and neither risk genotypes. If the two genes were synergetic, the odds ratio was significantly higher than only one each of the gene's odds ratio. It was shown that interaction between two genes caused multiplicative or additive risks (Szklo and Nieto 2000). According the Slutsky's theorem, the distribution of odds ratio via natural logarithm transformed was converged to normal distribution (Agresti 2002). In our data, the standard deviation was less then 1. The critical values of $95 \%$ of standard normal distribution with mean 0 and standard deviation 1 are +1.96 and -1.96 . The values 7.1 and 0.14 , the natural exponential of +1.96 and -1.96 , were significant thresholds of defining multiplicative risks. All statistical analyses were performed by SAS software (SAS 8.0, SAS Inc.)

\section{Results}

STR markers associated with significant difference between allergy and nonallergy asthma

Briefly described the Fig. 1 is the result of the whole autosomal genome region screened for loci associated with differences between allergic and nonallergic asthmatics. Normal and high IgE may be consistent with allergic and nonallergic asthma, as defined in the Material and methods section. Thirty-six STR markers were sought by allele and/or genotype frequency with significantly different $\operatorname{IgE}$ high and $\operatorname{IgE}$ normal groups (Table 1). The alleles of each locus were tested to odds ratio and $2 \times 2 \chi^{2}$ (data not shown) with other alleles of 
Table 6 List of candidate genes and related articles

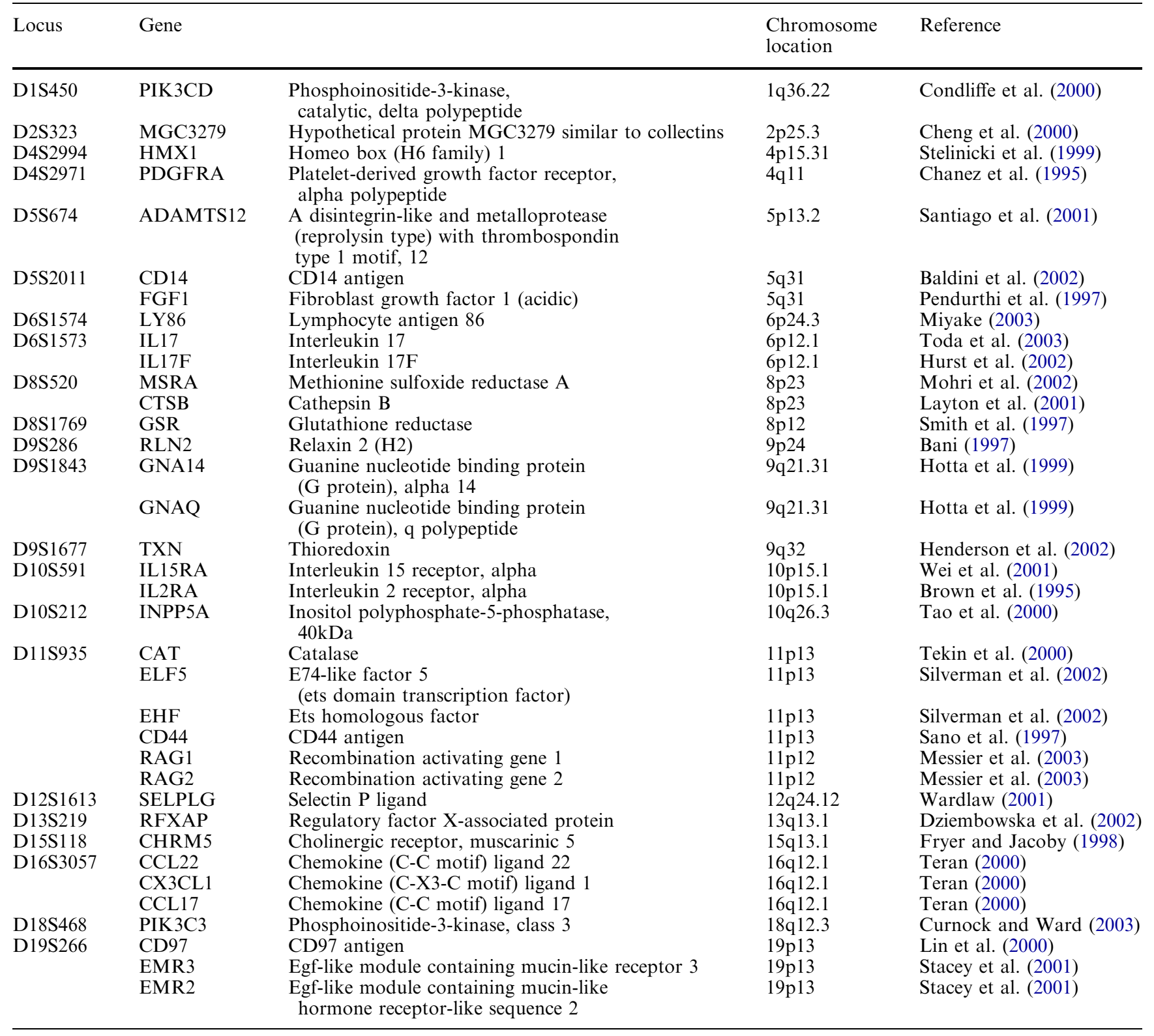

the same locus. In Table 1, the "Associated allele test" lists the alleles, which were statistically significant in the test. Eight loci-for example, D5S2011-have more than one associated allele. The genotypes of each associated allele were classified as homozygous and heterozygous then tested with odds ratio and $2 \times 2$ contingency table analysis (data not shown) with other genotypes of the same locus. The test results are shown in "Meaningful genotype test" in Table 1. Eighteen meaningful genotypes are shown in the dominant model (i.e., D5S2011) as having the same mean; the meaningful genotypes being homozygous and heterozygous was a risk factor for the two types of asthma compared with each other. Six meaningful genotypes were shown in the recessive model (i.e., D2S323), that is, the meaningful genotypes being homozygous was a risk factor for the two types of asthma compared with each other. All odd ratios are either larger than or smaller than one.

Discrimination for two forms of asthma by genotype data

Twenty-one of 36 significant STR markers were found on at least one meaningful genotype. Transformed binary data set contained information on 21 markers reduced by data transformation. Discrimination equation using the transformed binary data set was performed by logistic regression (Table 2). The combination equation of 11 markers that was generated by logistic regression without pro-selection can divide patients into two groups: high $\operatorname{IgE}(p>0.5)$ and normal $\operatorname{IgE}(p<0.5)$. The 
cut-off point of 0.5 was chosen, which showed 0.84 specificity and 0.23 sensitivity by receiver operating characteristic (ROC) curve analysis. Misclassification rate was 0.189 . The result implied that two type of asthma have a different genetic polymorphism background. The misclassification rate may be due to some asthmatics belonging to mixed type, or to other unrevealed genetic factors.

\section{Marker to marker synergetic effect}

To find the marker-to-marker synergetic effect in two forms of asthma, the $p$ values of Fisher's exact test for every marker-marker genotype combination associated with IgE status was used. Results are reported in Table 3. A $p$ value less than 0.05 is presented in bold. The marker orders were dependent on their chromosome location and are rearranged here for effective visualization. The matrix is partitioned into two triangles indicated by bold type and one rectangle indicated by normal type. To make sure whether there was a correlation between every two markers, the odds ratio of marker-to-marker genotype combinations was applied. The odds ratios of combined and single markers are listed in Table 4. Simulation using the resampling method was performed to evaluate the odds ratio generated by chance or not. The real correlation between two markers was maintained after resampling. On the other hand, the real correlation did not disappear due to different subgroups of total samples. For resampling, 152 subjects were randomly chosen from the 190 subjects and repeated 10,000 times. Table 5 displays the results of odds ratios after simulation. Markers D5S674, D6S1574, and D19S226 in the upper-left triangle combined with more than two markers had an increased odds ratio $(\mathrm{OR}<0.14)$ compared with those with a single marker. In the lower-right triangle, markers D5S2011, D6S1573, and D9S286 combined with more than one other marker and had a significantly decreased odds ratio $(\mathrm{OR}>7.1)$ compared with those with a single marker.

\section{Discussion}

According our investigation, 36 STR markers were significantly different between allergic and nonallergic asthma. Twenty-one of these 36 STR markers were found to have at least one meaningful genotype. Using an 11-marker combination equation generated by logistic regression and divided by cutoff points of $p=0.5$, we clearly show that these two forms of asthma have different genetic polymorphism backgrounds. Markerto-marker synergetic effect and simulation resampling tests revealed D5S2011, D6D1573, and D9S286 were important loci in allergic asthma while D5S674, D6S1574, and D19S226 were important in nonallergic asthma, with odds ratio $<0.14$ and $>7.1$, respectively. The results implied several genes, not just one major gene, contribute asthmatic genotype and phenotype in our studied subjects.

The STR markers, as multiallelic markers, always have more power to detect LD than do diallelic markers (such as SNPs) under otherwise equivalent conditions (Ott and Rabinowitz 1997; Chapman and Wijsman 1998). Power equivalent to that achieved by a multiallelic screen can theoretically be achieved by use of a denser diallelic screen, but mapping panels of the necessary resolution are not currently available and may be difficult to achieve. Theoretically, existing sets of microsatellite data, if sufficiently dense, can make initial predictions about the level of short-range LD present in susceptibility regions identified by linkage studies. These predictions can be useful for planning the density of markers needed for fine-mapping experiments (Schulze et al. 2002).

When analysis is restricted to members of reasonably well-defined ethnic or political groups, evidence of LD can frequently be found, with markers spanning the disease loci at 0.5-1.4 cM intervals (Wijsman 1997). Examples are found in Japanese (Goddard et al. 1996), Italians (Pandolfo et al. 1990), British (Votruba et al. 1998), and Poles (Brzustowicz et al. 1993). According to the above literature, candidate genes mentioned by previous references were selected, surrounding significant markers within $1 \mathrm{Mb}$ physical distance. They are listed in Table 6. Several markers had no known candidate genes nearby. Candidate genes were being divided into some functionally related categories as response to environmental factors (such as CD14), inflammation (cytokines, cytokine receptors, chemokines), remodeling (FGF1, ADAMTS12, PDGFRA and epidermal growth factor), and others (transcription related genes, kinase). From another view, those candidate genes may imply or indicate that there is some biological pathway or mechanism related to asthma development, such as IL2RA, IL15RA, RAG1, and RAG2 in cytokine and signaling pathways related to immunodeficiencies (Schluns and Lefrancois 2003; Candotti et al. 2002); CD14 and Ly86 in innate recognition of lipopolysaccharides (Miyake 2003); and CCL17 and CCL12 correlated with the recruitment of specific leukocyte subsets expressing the receptors for those chemokines in asthma and other pulmonary diseases (D'Ambrosio et al. 2003).

Our findings have clearly showed that, even in a very homogenous population, the susceptible genes for the concentration of serum IgE and responsive to environmental aeroallergens were quite different in asthmatic children. Although the difference of clinical manifestations between these two forms of asthma are not so prominent as in adult asthmatics, nonallergic asthmatic children tend to have a higher frequency of asthmatic attacks with more adherence to controlled medications and are also more prone to have airway remodeling than those with allergic asthma (Romanet-Manent et al. 2002; Inouye et al. 1985). Our results have demonstrated that 
these two forms of asthma are governed by two different sets of susceptible genes that lead to common end results of eosinophilic bronchial inflammation found in all asthmatic patients. It is also strongly suggested that, in fact, allergic and nonallergic asthma are two different clinical entities that demand a different consideration and management in the prevention and treatment of childhood asthma.

Acknowledgements We thank Dr. John Gu for comments on the manuscript, Dr. Ashely Ching-Wei Chang for comments on statistical analysis, Ms. Julia $\mathrm{Yu}$ and Ms. Jiayu Huang for data management, and Ms. Brook Teng for administrative support.

\section{References}

Agresti A (2002) Categorical data analysis, 2nd edn. Wiley, Hoboken NJ

Baldini M, Vercelli D, Martinez FD (2002) CD14: an example of gene by environment interaction in allergic disease. Allergy 57:188-192

Bani D (1997) Relaxin: a pleiotropic hormone. Gen Pharmacol 28:13-22

Bentley AM, Menz G, Storz C, Robinson B, Jeffery PK, Durham SR, Kay AB (1992) Identification of T lymphocytes, macrophages, and activated eosinophils in bronchial mucosa in intrinsic asthma. Am Rev Respir Dis 146:500-506

Brown JE, Greenberger PA, Yarnold PR (1995) Soluble serum interleukin 2 receptors in patients with asthma and allergic bronchopulmonary aspergillosis. Ann Allergy Asthma Immunol 74:484-488

Brzustowicz LM, Matseoane D, Wang CH, Kleyn PW, Vitale E, Penchaszadeh GK, Hausmanowa-Petrusewicz I, Gilliam TC (1993) Linkage disequilibrium and haplotype analysis among Polish families with spinal muscular atrophy. Am J Hum Genet Suppl 53:982

Burney PG, Luczynska C, Chinn S, Jarvis D (1994) The European Community Respiratory Health Survey. Eur Respir J 5:954-960

Burrows B, Martinez FD, Halonen M, Barbee RA, Cline MG (1989) Association of asthma with serum IgE levels and skintest reactivity to allergens. N Engl J Med 320:271-277

Candotti F, Notarangelo L, Visconti R, O'Shea J (2002) Molecular aspects of primary immunodeficiencies: lessons from cytokine and other signaling pathways. J Clin Invest 109:1261-1269

Chanez P, Vignola M, Stenger R, Vic P, Michel FB, Bousquet J (1995) Platelet-derived growth factor in asthma. Allergy 50:878-883

Chapman NH, Wijsman EM (1998) Genome screens using linkage disequilibrium tests: optimal marker characteristics and feasibility. Am J Hum Genet 63:1872-1885

Cheng G, Ueda T, Numao T, Kuroki Y, Nakajima H, Fukushima Y, Motojima S, Fukuda T (2000) Increased levels of surfactant protein $\mathrm{A}$ and $\mathrm{D}$ in bronchoalveolar lavage fluids in patients with bronchial asthma. Eur Respir J 16:831-835

Condliffe AM, Cadwallader KA, Walker TR, Rintoul RC, Cowburn AS, Chilvers ER (2000) Phosphoinoditide 3-kinase: a critical signaling event in pulmonary cells. Respir Res 1:24-29

Cookson W (1999) The alliance of genes and environment in asthma and allergy. Nature 402(Suppl):B5-B11

Curnock AP, Ward SG (2003) Development and characterisation of tetracycline-regulated phosphoinositide 3-kinase mutants:assessing the role of multiple phosphoinositide 3-kinases in chemokine signalling. J Immunol Methods 273:29-41

D'Ambrosio D, Panina-Bordignon P, Sinigaglia F (2003) Chemokine receptors in inflammation: an overview. J Immunol Methods 273:3-13
Davies DE, Wicks J, Powell RM, Puddicombe SM, Holgate ST (2003) Airway remodeling in asthma: new insights. J Allergy Clin Immunol 111:215-225

Dorward AJ, Colloff MJ, MacKay NS, McSharry C, Thompson NC (1988) Effect of house dust mite avoidance measures on adult atopic asthma. Thorax 43:98-102

Dziembowska M, Fondaneche MC, Vedrenne J, Barbieri G, Wiszniewski W, Picard C, Cant AJ, Steimle V, Charron D, Alca-Loridan C, Fischer A, Lisowska-Grospierre B (2002) Three novel mutations of the CIITA gene in MHC class IIdeficient patients with a severe immunodeficiency. Immunogenetics 53:821-829

Fryer AD, Jacoby DB (1998) Muscarinic receptors and control of airway smooth muscle. Am J Respir Crit Care Med 158(5 Pt 3):S154-S160

Goddard KA, Yu CE, Oshima J, Miki T, Nakura J, Piussan C, Martin GM, Schellenberg GD, Wijsman EM (1996) Towards localization of the Werner syndrome gene by linkage disequilibrium and ancestral haplotyping: lessons learned from analysis of 35 chromosome 8p11.1-21.1 markers. Am J Hum Genet 58:1286-1302

Henderson WRJ, Chi EY, Teo JL, Nguyen C, Kahn M (2002) A small molecule inhibitor of redox-requlated NF-kappa B and activator protein-1 transcription blocks allergic airway inflammation in a mouse asthma model. J Immunol 169:5294-5299

Holgate ST, Davies DE (2001) Airway inflammation and remodeling in asthma - cause and effect?. Immunologist 8:131-135

Hotta K, Emala CW, Hirshman CA (1999) TNF-alpha upregulates Gialpha and Gqalpha protein expression and function in human airway smooth muscle cells. Am J Physiol 276(3 Pt 1):L405-411

Humbert M, Grant JA, Tabora-Barata L, Durham SR, Pfister R, Menz G, Barkans J, Ying S, Kay AB (1996a) High affinity IgE receptor $(\mathrm{Fc} \in \mathrm{RI})$ bearing cells in bronchial biopsies from atopic and non-atopic asthma. Am J Respir Crit Care Med 153:19311937

Humbert M, Durham SR, Ying S, Kimmit P, Barkans J, Assoufi B, Pfister R, Menz G, Robinson DS, Kay AB et al (1996b) IL-4 and IL-5 mRNA and protein in bronchial biopsies from patients with atopic and nonatopic asthma: evidence against "intrinsic" asthma being a distinct immunopathologic entity. Am J Respir Crit Care Med 154:1497-1504

Humbert M, Ying S, Corrigan CJ, Menz G, Pfister J, Meng Q, Van Damme J, Opdenakker G, Durham SR, Kay AB (1997a) Bronchial mucosal expression of the genes encoding chemokines RANTES and MCP-3 in symptomatic atopic and nonatopic asthmatics: relationship to eosinophil-active cytokines IL-5, GM-CSF and IL-3. Am J Resp Cell Mol Biol 16:1-8

Humbert M, Durham SR, Kimmit P, Assoufi B, Pfister R, Menz G, Lay AB, Corrigan CJ (1997b) Elevated expression of messenger ribonucleic acid encoding IL-13 in the bronchial mucosa of atopic and non-atopic subjects with asthma. J Allergy Clin Immuno 99:657-665

Humbert M, Menz G, Ying S, Corrigan CJ, Robison DS, Durham SR Kay AB (1999) The immunopathology of extrinsic (atopic) and intrinsic (non-atopic) asthma: more similarities than differences. Immunol Today 20:528-533

Hurst SD, Muchamuel T, Gorman DM, Gilbert JM, Clifford T, Kwan S, Menon S, Seymour B, Jackson C, Kung TT, Brieland JK, ZAurawski SM, Chapman RW, Zurawski G, Coffman RL (2002) New IL-17 family members promote Th1 or Th2 responses in the lung: in vivo function of the novel cytokine IL25. J Immunol 169:443-453

Inouye T, Tarlo S, Broder I, Corey P, Davies G, Leznoff A, Mintz S, Thomas P (1985) Severity of asthma in skin-test negative, and skin test-positive patients. J Allergy Clin Immunol 75:313319

Layton GT, Harris SJ, Bland FA, Lee SR, Fearn S, Kaleta J, Wood ML, Bond A, Ward G (2001) Therapeutic effects of cysteine protease inhibition in allergic lung inflammation: inhibition of allergen-specific T lymphocyte migration. Inflamm Res 50:400-408 
Lin HH, Stacey M, Hamann J, Gordon S, McKnight AJ (2000) Human EMR2, a novel EGF-TM7 molecule on chromosome 19 p13.1, is closely related to CD97. Genomics 67:188-200

Messier TL, O'Neill JP, Hou SM, Nicklas JA, Finette BA (2003) In vivo transposition mediated by $\mathrm{V}(\mathrm{D}) \mathrm{J}$ recombinase in human $\mathrm{T}$ lymphocytes. EMBO J 22:1381-1388

Miyake K (2003) Innate recognition of lipopolysaccharide by CD14 and toll-like receptor 4-MD-2: unique roles for MD-2. Int Immunopharmacol 3:119-128

Mohri M, Reinach PS, Kanayama A, Shimizu M, Moskovitz J, Hisatsune T, Miyamoto Y (2002) Suppression of the TNFalpha-induced increase in IL-lalpha expression by hypochlorite in human corneal epithelial cells. Invest Ophthalmol Vis Sci 43:3190-3195

Ott J, Rabinowitz D (1997) The effect of marker heterozygosity on the power to detect linkage disequilibrium. Genetics 147:927930

Pandolfo M, Sirugo G, Antonelli A, Weitnauer L, Ferretti L, Leone M, Dones I, Cerina A, Fujita R, Hanauer A et al (1990) Friedreich ataxia in Italian families: genetic homogeneity and linkage disequilibrium with the marker loci D9S5 and D9S15. Am J Hum Genet 47:228-235

Pearce N, Sunyer J, Cheng S, Chinn S, Bjorksten B, Burr M, Keil U, Anderson HR, Burney P (2000) Comparison of asthma prevalence in the ISAAC and the ECRHS. ISAAC steering committee and the European community respiratory health survey. International study of asthma and allergies in childhood. Eur Respir J 16:420-426

Pendurthi UR, Williams JT, Rao LV (1997) Acidic and basic fibroblast growth factors suppress transcriptional activation of tissue factor and other inflammatory genes in endothelial cells. Arterioscler Thromb Vasc Biol 17:940-946

Rackeman FM (1947) A working classification of asthma. Am J Med 3:601

Romanet-Manent S, Charpin D, Magnan A, Lantaume A, Vervloet D, The EGEA Cooperative Group (2002) Allergic vs nonallergic asthma: what makes the difference? Allergy 57:607613

Sano K, Yamauchi K, Hoshi H, Honma M, Tamura G, Shirato K (1997) CD44 expression on blood eosinophils is a novel marker of bronchial asthma. Int Arch Allergy Immunol 114(Suppl 1):67-71

Santiago C, Arguelles JM, Fernandez PL, Lopez-Otin C (2001) Identification, characterization, and intracellular processing of ADAM-TS12, a novel human disintegrin with a complex structural organization involving multiple thrombospondin-1 repeats. J Biol Chem 276:17932-17940

Schluns KS, Lefrancois L (2003) Cytokine control of memory Tcell development and survival. Nat Rev Immunol 3:269-279

Schulze TG, Chen YS, Akula N, Hennessy K, Badner JA, McInnis MG, DePaulo JR, Schumacher J, Cichon S, Propping P, Maier W, Rietschel M, Nothen MM, McMahon FJ (2002) Can longrange microsatellite data be used to predict short-range linkage disequilibrium? Hum Mol Genet 11:1363-1372

Sham PC, Curtis D (1995) Monte Carlo tests for associations between disease and alleles at highly polymorphic loci. Ann Hum Genet 59:97-105
Silverman ES, Baron RM, Palmer LJ, Le L, Hallock A, Subramaniam V, Riese RJ, McKenna MD, Gu X, Libermann TA, Tugores A, Haley KJ, Shore S, Drazen JM, Weiss ST (2002) Constitutive and cytokine-induced expression of the ETS transcription factor ESE-3 in the lung. Am J Respir Cell Mol Biol 27:697-704

Smith LJ, Shamsuddin M, Sporn PH, Denenberg M, Anderson J (1997) Reduced superoxide dismutase in lung cells of patients with asthma. Free Radic Biol Med 22:1301-1307

Stacey M, Lin HH, Hilyard KL, Gordon S, McKnight AJ (2001) Human epidermal growth factor (EGF) module-containing mucin-line hormone receptor 3 is a new member of the EGFTM7 family that recognizes a ligand on human macrophages and activated neutrophils. J Biol Chem 276:18863-18870

Stelnicki EJ, Chin GS, Gittes GK, Longaker MT (1999) Fetal wound repair: where do we go from here? Semin Pediatr Surg 8:124-130

Szklo M, Nieto FJ (2000) Epidemiology: beyond the basics. Aspen Publisher Inc., Gaithersburg, MD

Tao FC, Tolloczko B, Mitchell CA, Powell WS, Martin JG (2000) Inositol $(1,4,5)$ trisphosphate metabolism and enhanced calcium mobilization in airway smooth muscle of hyperresponsive rats. Am J Respir Cell Mol Biol 23:514-520

Tekin D, Sin BA, Mungan D, Misirligil Z, Yavuzer S (2000) The antioxidative defense in asthma. J Asthma 37:59-63

Teran LM (2000) CCL chemokines and asthma. Immunol Today $21: 235-242$

Toda M, Leung DY, Molet S, Boguniewicz M, Taha R, Christodoulopoulos P, Fukuda T, Elias JA, Hamid QA (2003) Polarized in vivo expression of IL-11 and IL17 between acute and chronic skin lesions. J Allergy Clin Immunol 111:875-881

Votruba M, Moore AT, Bhattacharya SS (1998) Demonstration of a founder effect and fine mapping of dominant optic atrophy locus on 3q28-qter by linkage disequilibrium method: a study of 38 British Isles pedigrees. Hum Genet 102:79-86

Wardlaw AJ (2001) Eosinophil trafficking in asthma. Clin Med $1: 214-218$

Wei XQ, Orchardson M, Gracie JA, Leung BP, Gao BM, Guan H, Niedbala W, Paterson GK, McInnes IB, Liew FY (2001) The Sushi domain of soluble IL-15 receptor $\alpha$ is essential for binding IL-15 and inhibiting inflammatory and allogenic responses in vitro and in vivo. J Immunol 167:277-282

Wijsman EM (1997) Association versus linlage analysis in mental disorders. In: Blum K, Noble EP (eds) Handbook of psychiatric genetics. CRC Press, New York, pp 7-24

Ying S, Humbert M, Barkans J, Corrigan CJ, Pfister R, Menz G, Robinson DS, Larche M, Durham SR, Kay AB (1997) Expression of IL-4 and IL-5 mRNA and protein product by $\mathrm{CD}^{+}$and $\mathrm{CD} 8^{+} \mathrm{T}$ cells, eosinophils and mast cells in bronchial biopsies obtained from atopic and non-atopic (intrinsic) asthmatics. J Immunol 158:3539-3544

Ying S, Meng Q, Zeibecoglou K, Robinson DS, Macfarlane A, Humbert M, Kay AB (1999) Eosinophil chemotactic chemokines (eotaxin, eotaxin-2, RANTES, monocyte chemoattractant protein-3 (MCP-3), and MCP-4), and C-C chemokine receptor 3 expression in bronchial biopsies from atopic and nonatopic (Intrinsic) asthmatics. J Immuno 163:6321-6329 